\title{
LAS GUERRAS DE LA EX YUGOSLAVIA EN LA CREACIÓN DRAMÁTICA FEMENINA ESPAÑOLA
}

\author{
MARÍA LUISA GARCÍA-MANSO
}

Universität Passau. Alemania mai.gmanso@gmail.com

RESUMEN: Las guerras de secesión de la antigua Yugoslavia (1991-2001) causaron una gran conmoción en la sociedad española. Las imágenes mostradas en la televisión y la prensa se convirtieron en el desencadenante de la creación dramática de varias autoras españolas que comenzaron su andadura escénica entre los años noventa y principios del siglo XXI. Las seis obras dramáticas incluidas en este estudio - Fuga (1994), de Itziar Pascual; Los días perdidos (1997), de Eva Hibernia; La ciudad sitiada (1997), de Laila Ripoll; Un lugar estratégico (2005), de Gracia Morales; Belgrado (2008), de Angélica Liddell; y laSal (2012), de Eva Hibernia- permiten plantear diversas cuestiones en torno al impacto de género de las guerras, el papel de la comunidad internacional y la representación del horror en el teatro.

PALABRAS CLAVE: Teatro español contemporáneo, género, Yugoslavia, guerra. 


\section{EX-YUGOSLAV WARS IN SPANISH WOMEN WRITERS DRAMATIC WORKS}

ABSTRACT: The Yugoslav Wars (1991-2001) sent shockwaves through Spanish society. The images broadcast in the media triggered the creation of plays by several female Spanish playwrights, who began to publish and stage their works between the 1990s and the early 21 st century. The six plays included in this essay —Fuga (1994) by Itziar Pascual, Los días perdidos (1997) by Eva Hibernia, La ciudad sitiada (1997) by Laila Ripoll, Un lugar estratégico (2005) by Gracia Morales, Belgrado (2008) by Angélica Liddell, and laSal (2012) by Eva Hibernia - raise questions about the impact of gender on war, the role of the international community and the representation of horror in theatre.

KEYWORDS: Contemporary Spanish drama, gender, Yugoslavia, war

a indagación en la memoria colectiva ocupa un lugar prioritario dentro del drama histórico contemporáneo (Vilches de Frutos, 2002; Floeck, 2006). En la escena española de los últimos años es frecuente encontrar propuestas dramáticas históricas en las que se plantean reflexiones sobre las guerras que tuvieron lugar en el siglo $\mathrm{XX}$ y sus consecuencias en nuestros días. El interés de los autores $\mathrm{y}$ autoras de teatro se ha dirigido especialmente a reflexionar sobre acontecimientos que han marcado la historia española reciente, como la Guerra Civil, el exilio republicano de 1939 o la dictadura franquista. Sin embargo, existe también un importante grupo de obras en las que se plantean sucesos de acuciante actualidad que han tenido lugar más allá de las fronteras nacionales, mostrando otros escenarios de violencia. Así ocurre, en efecto, con el considerable conjunto de tex- tos dramáticos que, en un tono antibelicista y de denuncia, evocan algunas de las guerras recientes que mayor impacto han tenido en la conciencia colectiva española (Ragué-Arias, 2005: 13).

En los años noventa, coincidiendo con la aparición de una nueva generación de autoras de teatro (Serrano, 2004: 567; GarcíaManso, 2013: 121), se estaban produciendo en la Europa de los Balcanes las guerras de secesión yugoslavas. Las imágenes de violencia y destrucción, transmitidas de forma cotidiana en los medios de comunicación, causaron una tremenda conmoción en la sociedad europea. El estallido del conflicto, iniciado en 1991 en la actual Eslovenia, fue mudando de escenarios, territorios y bandos contendientes hasta 2001. A lo largo de aquellos diez años, los diferentes grupos étnicos de la antigua Yugoslavia se enfrentaron en guerras de fatídicas consecuencias. Millones de personas tuvieron que desplazarse y vivir en campos de refugiados y las víctimas mortales se cuentan en cientos de miles de personas. Todavía hoy permanecen grabadas en la conciencia colectiva las imágenes del horror que, difundidas por los medios de comunicación cada día, informaban del transcurso del conflicto.

La proximidad geográfica de estas guerras y la violencia infringida contra la población civil y especialmente contra las mujeres ha contribuido a despertar el interés de las creadoras españolas del ámbito escénico. Las cinco autoras de las obras dramáticas incluidas en este ensayo proceden de una generación que comienza su andadura en el teatro en los años noventa. Laila Ripoll (Madrid, 1964), Angélica Liddell (Figueras, Gerona, 1966), Itziar Pascual (Madrid, 1967), Eva Hibernia (Logroño, 1973) y Gracia Morales (Motril, Granada, 1973) cuentan en la actualidad con una trayectoria consolidada en el ámbito escénico y muestran una especial predilección por el tratamiento de temáticas comprometidas.

Nos vamos a referir a un total de seis textos dramáticos en los que las guerras de los Balcanes se sitúan como trasfondo: Fuga (1994), de Itziar Pascual; Los días perdidos (1997), de Eva Hibernia; La ciudad sitiada (1997), de Laila Ripoll; Un lugar estratégico (2005), de Gracia Morales; Belgrado (2008), de Angélica Liddell y laSal (2012), de Eva 
Hibernia. En ellos, las autoras parten de la terrible realidad bélica para plantear las consecuencias de la violencia sobre la comunidad y, especialmente, sobre las mujeres. Sin embargo, la representación de un conflicto tan complejo y reciente que, en algunos casos, se encontraba activo en el momento de la creación dramática, suscita cuestiones en torno al despertar de los procesos creativos y su plasmación en los textos dramáticos y en la escena. ¿Cuál fue el desencadenante de la creación de estos textos? ¿Cómo se produce en ellos la representación del horor? En este artículo nos proponemos analizar las formas dramáticas utilizadas por las autoras españolas contemporáneas para reflexionar sobre estas guerras y sus consecuencias sobre las víctimas civiles que el lenguaje ha denominado eufemísticamente como "colaterales".

El primer aspecto que cabe destacar sobre este conjunto de obras es que se trata de un teatro en el que el documento, el testimonio y la imagen difundidos a través de los medios de comunicación son determinantes para la selección del tema y la construcción dramática. Al igual que ocurre con la representación dramática de otras temáticas extraídas de la realidad social, como la inmigración y la xenofobia (García-Manso, 2012: 288-89), el acceso a los canales de información en red y las nuevas tecnologías se constituyen como fuentes esenciales de los procesos creativos. Con frecuencia, las autoras aluden en los programas de mano, los prólogos de los textos dramáticos o en entrevistas sobre los montajes escénicos al impacto que las imágenes y noticias de la prensa y la televisión produjeron en su conciencia.

Itziar Pascual, una de las primeras autoras que se inspira en dichas guerras, explica en el programa de mano de Fuga cómo se vio conminada a la escritura de la obra: "en el verano de 1993 me acompañaron las siluetas del horror. Las voces de mujeres agredidas por la barbarie, las imágenes de la naturaleza abatida por la eficaz destrucción humana, se mezclaban con reflexiones más íntimas..." (Galindo, 1995: 81). También Eva Hibernia alude a motivos similares en relación a Los días perdidos, inspirada por una terrible fotografía publicada en la prensa:
Ese año [1996], el ingente bombardeo de noticias sobre la guerra de los Balcanes, dio de lleno en un lugar de mi conciencia que quiso reaccionar en la manera en que sé hacerlo como artista: escribiendo un texto. Recuerdo que el detonante fue una imagen que acompañaba esa mañana la noticia del periódico. (Hibernia, 2012: 11-12)

Tal y como señala Luis Araújo en su prólogo a la edición de Los días perdidos, se trata de una imagen de un "niño mutilado de guerra en Bosnia, cuya fotografía ha dado la vuelta al mundo" (Araújo, 1997: 5). La imagen de este niño, además, se incorpora al drama a través de las alusiones de sus personajes, quienes señalan verlo en diversas ocasiones, sin que se manifieste ante el público. Laila Ripoll reconoce asimismo la influencia de las crudas noticias sobre la guerra en la escritura de La ciudad sitiada1: "era tremendamente doloroso desayunar todas las mañanas con aquello que estaba sucediendo. Era el año 95 y recuerdo las violaciones de las mujeres bosnias, a las que luego sus propios compañeros les abrían el vientre para sacar a los hijos, porque eran de otra raza. Era un grado de horror..." (Ripoll, 2011: 27). Al igual que Hibernia, Ripoll se refiere a una imagen que se convirtió en el detonante de su proceso creativo: "Recuerdo una foto de una chica musulmana muy joven y guapa, sin piernas, en un bombardeo, recuerdo unos pies que nos impresionaron... y surgió la escritura de este texto" (28). La joven mutilada aparece en la obra representada en el personaje de la Muchacha, cuyo monólogo da comienzo a la acción.

Mientras que Fuga, Los días perdidos y La ciudad sitiada se escribieron al calor de los enfrentamientos bélicos, la génesis de Un lugar estratégico, de Gracia Morales, Belgrado, de Angélica Liddell, y

\footnotetext{
${ }^{1}$ La compañía Micomicón, fundada y dirigida por Laila Ripoll, realizó una gira de tres meses por Centroamérica en 1996. En Suchitoto, "la ciudad más castigada por la cruenta guerra civil de El Salvador", realizaron una lectura de El cerco de Numancia, de Miguel de Cervantes. La autora se refiere a que el público se vio reflejado "en el viacrucis del pueblo numantino" y señala que fue "esta emocionante experiencia, unida a los recuerdos de su propia abuela acerca de la Guerra Civil española y a las impresiones sobre el terrible drama de la Guerra de los Balcanes", lo que inspiró la creación de La ciudad sitiada (Guzmán, 1999: 14).
} 
laSal, de Eva Hibernia, se produce con posterioridad a los mismos, cuando sus consecuencias son más perceptibles. El texto de Gracia Morales nace a raíz de un viaje que la autora realiza en 2002 a los Balcanes. Allí conoce la historia de la destrucción, en 1993, del puente medieval de Mostar, en Bosnia-Herzegovina (Martínez, 2003: 62), lo que inspiró la escritura de Un lugar estratégico y su localización en un histórico puente. Angélica Liddell, por su parte, escribe Belgrado tras una aproximación personal a un conflicto que, según señala, había pasado desapercibido para ella: "Belgrado surge porque no me di cuenta de la guerra de los Balcanes, de hacerla pasar por mi memoria o comprensión y me negaba a que eso quedara fuera de una especie de memoria especial, y la quise hacer pasar por el pensamiento, por mi experiencia individual, y surge de aspectos más filosóficos" ("Angélica”, 2008). De igual manera, laSal, segunda obra de Eva Hibernia basada en las guerras de la ex Yugoslavia, se escribe tras un concienzudo proceso de documentación, como explica la autora: "De nuevo hice una inmersión documentándome sobre el conflicto, incluso tuve el privilegio de tener una apasionante charla-conferencia con un especialista sobre el tema, Paco Veiga" (Hibernia, 2012: 13).

Por otra parte, los seis textos dramáticos comparten una misma preocupación por visibilizar el impacto de género que tiene la guerra en la vida de mujeres y hombres. En todos ellos se incorporan interesantes reflexiones sobre cómo se ven agravadas las desigualdades de género en el contexto bélico o en la posguerra. Tal y como señala Carmen Herrero, "el análisis de la violencia, de lo arbitrario e irracional que hay en la misma, es el recurso del que se sirven estas dramaturgas para deconstruir el discurso patriarcal y las estructuras político-sociales que lo sustentan al mostrar a hombres y mujeres como víctimas" (2001: 355). Los personajes femeninos se convierten en víctimas de diversos abusos y violaciones cuya finalidad es resquebrajar el orden familiar, entendido como microcosmos de la nación ${ }^{2}$.

2 "Women often come to symbolise national and collective honour. [...] Because of this construction of womanhood as epitomising the collectivity, systematic rapes have become part of warfare, as in Bosnia" (Yuval-Davis, 1997: 196).
Si bien las autoras de estos textos comparten un mismo compromiso personal ante la dura realidad de las guerras, su manera de encarar la materia dramática y de darle forma es diferente. Todas ellas crean para sus obras personajes anónimos que, en algunos casos - Fuga, La ciudad sitiada y Un lugar estratégico-, se identifican únicamente mediante nombres comunes (Mujer, Hombre, Vagabunda, Náufrago...). Además, en la mayoría de los dramas, las autoras tienden a desdibujar el trasfondo histórico que les ha servido de inspiración, deslocalizando la acción dramática e incluso situándola en lugares y tiempos simbólicos. Esta elusión del marco histórico permite tratar con mayor libertad el tema de la guerra y universalizar el alegato antibelicista, especialmente en aquellas obras que se escribieron cuando el conflicto aún estaba activo. Tal y como señala Francisca Vilches de Frutos, esta omisión de los referentes históricos constituye una tendencia habitual del drama histórico contemporáneo: "Si bien algunas creaciones se inspiran de manera directa en hechos históricos del pasado más inmediato o del presente [...], lo habitual es que estas obras no ofrezcan una referencia directa a hechos históricos concretos" (Vilches de Frutos, 1999: 90).

El primer texto publicado y estrenado es Fuga, de Itziar Pascual, una obra que transcurre en un espacio casi mítico y atemporal, con personajes simbólicos, alegóricos e incluso inspirados en arquetipos de la mitología grecolatina. La autora opta así por universalizar el tema de la guerra y situarlo en la imaginaria Isla del Sueño, enfrentada en una guerra devastadora con la Isla del Aire. Contamos con dos versiones del texto dramático, la primera de ellas, impresa en 1994 por el Centro Nacional de Nuevas Tendencias Escénicas, y la segunda, con fecha de agosto de 2005, publicada en internet por CELCIT -Centro Latinoamericano de Creación e Investigación Teatral. La segunda versión amplía el texto dramático original añadiendo dos canciones, entonadas por los personajes de la Nodriza y Ariadna, y tres diálogos mantenidos por Cautela y Arrojo, dos personajes que no aparecen en la primera versión del drama y que le otorgan un marco narrativo ${ }^{3}$.

3 Dicha versión es más cercana a la utilizada en el montaje dirigido por Guillermo Womutt [Teatro Pradillo, Madrid, 20-4-1995], en el que la música y el espacio sonoro cobraron una vital importancia.

UNED. REI, 2 (2014), pp. 145-169

ISSN 2340-9029 
El texto se compone fundamentalmente de monólogos de marcado carácter poético. Casi todos los personajes aparecen identificados por nombres comunes que permiten situarlos en el contexto bélico como protagonistas de la guerra o como sus víctimas -la Harapienta, la Nodriza, el Vigía, el Náufrago, el Soldado...-, mientras que otros aparecen identificados con nombres alegóricos -Arrojo y Cautela-, o con nombres propios, como es el caso de Anthropos, señor de Bellver y dueño de la Isla del Sueño, y Ariadna, su hija, que como la del mito pasa su tiempo "entre brocados y agujas" y se identifica a sí misma con la paciente Penélope, conminada también a esperar por el regreso de un hombre (Pascual, 2005: 10).

Cautela y Arrojo son almas en pena que se encuentran "entre el sueño y la última vigilia" (Pascual, 2005: 1). Ambas lamentan la destrucción que la guerra ha causado en la Isla del Sueño y se proponen "alumbrar" su memoria, con el fin de que "alguien inicie los nuevos tiempos [...] del hombre libre" (2). A continuación, los habitantes de la obra van pronunciando monólogos que ofrecen miradas diversas sobre la guerra: desde la Nodriza que pide venganza contra los que llevaron a su hijo a la muerte, hasta el Náufrago que clama por la paz o el Soldado que cuestiona su propia sumisión a la autoridad militar. Al final de la obra, el personaje de la Harapienta lleva a cabo un alegato por la paz y la clemencia, advirtiendo que sólo la compasión por el enemigo puede poner fin a la guerra. Siguiendo la estela de la protagonista de La tumba de Antígona, de María Zambrano, la Harapienta se convierte en la voz de la conciencia colectiva. Arrojo y Cautela parecen emular las palabras de los dos Desconocidos del drama zambraniano ${ }^{4}$ :

Cautela: En la Isla del Sueño el tiempo se detuvo. La voz de la Harapienta llamó al pueblo de Bellver.

Arrojo: ¿Y lo llamará?

4 "Desconocido Primero: [...] ¿Quieres decir que [Antígona] va a seguir aquí sola hablando en alta voz, muerta hablando a viva voz para que todos la oigamos? ¿Es que va a tener vida, y voz? / DESCONOCIDO SEGUNDO: Sí; vida y voz tendrá mientras siga la historia" (Zambrano 1983: 84).
Cautela: Y lo llama. Hay preguntas que se arrastran por la Eternidad para ser contestadas. Dejémosles solos.

Arrojo: ¿A quiénes?

Cautela: La Harapienta envía su voz entre las sombras. Puede que esta noche alguien la escuche. (Pascual, 2005: 16)

En Los días perdidos (1997) ${ }^{5}$, de Eva Hibernia, son varios los aspectos que permiten relacionar el drama con la guerra de Bosnia y el asedio de Sarajevo, aunque no se mencionen de forma directa en el transcurso de la acción, haciendo posible de nuevo la universalización del tema de la guerra. Una breve nota introductoria de la autora apunta a la existencia de un conflicto abierto: "Tiempo después de escribir la primera versión de esta obra, llegaron más noticias sobre el horror" (Hibernia, 1997: 11). En el propio texto dramático se hallan sucintas referencias a la guerra en Bosnia. Por ejemplo, en la primera acotación de la obra se alude a una ciudad "enquistada de guerra" en el centro de Europa:

Ciudad en el corazón ocasional de Europa, donde se abre una fosa común. Ciudad cementerio, enquistada de guerra, en la que rostros, nombres y bandos esperan la verdad oficial de la Historia. Pero una gran ignorancia se ha olvidado de esta ciudad, de esta calle, a pesar del atasco de noticias en la sección internacional de los periódicos, ocupados los cirujanos de la comunitaria beca en fabricar otros corazoncillos de rápida implantación en congresos y charlas y apretones de manos. Es así que verdean las patitas de Europa, la vaquita que ríe. Un tiempo artificial, ese de las máquinas que mantienen a los muertos, se posa en los deshechos y las ruinas, y porque amanece lo llaman día. (Hibernia, 1997: 17)

${ }^{5}$ Esta obra dramática recibió una Ayuda de Creación de la Comunidad de Madrid en 1996. Ha sido representada "en circuitos amateurs y universitarios" (Hibernia 2012: 13), como es el caso del montaje realizado en 2002 por la compañía Watabata, conformada por estudiantes de varias facultades de la Universidad Complutense de Madrid ("No te lo pierdas").

UNED. REI, 2 (2014), pp. 145-169

ISSN 2340-9029 
Más adelante, las repetidas referencias que hacen los personajes a los “azules" (Hibernia, 1997: 34, 80), "azulitos" (18, 20) o "soldaditos azules" (21) permiten asociar nuevamente la materia dramática con la guerra de Bosnia, donde estuvieron destinadas las Fuerzas de Paz de la ONU, también conocidas como "cascos azules". Además, se introduce en la escena quinta ("Tarde") un mensaje de radio que anuncia que va a haber una tregua con motivo de la visita del Papa (85), que finalmente es anulada (101). Este conato de visita estuvo a punto de producirse en 1994 durante el asedio de Sarajevo por el entonces Papa Juan Pablo II, pero se canceló por motivos de seguridad. Por último, los personajes se refieren en varias ocasiones a un niño con muletas, que el público no puede ver pero que les causa una gran conmoción. Dicho niño, tal y como explica Araújo en su prólogo, es el niño mutilado que inspiró a la autora para escribir la obra, y que ha sido introducido a modo de "obsesión" visual en la misma (Araújo, 1997: 6-7). Así pues, es posible concretar una realidad espacial y temporal de referencia para la acción dramática, si bien la autora ha optado por desdibujar dicho contexto con el fin de universalizar la repercusión del conflicto, un aspecto que se verá reforzado a través de la configuración de los personajes.

El texto dramático se estructura en siete escenas que representan cada momento del día, completando un ciclo de 24 horas ("Madrugada", "Mañana”, "Ruleta del mediodía”, "Siesta”, “Tarde”, "Noche" y "Madrugada"). El protagonismo del drama es colectivo, aunque cada uno de los catorce personajes cuenta con una dimensión propia. Las diversas escenas muestran las dificultades que deben sortear los habitantes en su día a día: el hambre, los bombardeos y francotiradores, las colas para recibir alimentos de los "cascos azules", el estraperlo, el dolor por los seres queridos perdidos y la añoranza de los tiempos de paz, etc., pero también se intercalan momentos en los que la solidaridad y amistad establecida entre algunos personajes arroja luz sobre la barbarie. La compleja cotidianeidad de esta ciudad en guerra se rompe cuando el Enterrador, compañero de juegos de la pequeña Alba, mata a la Usurera al descubrir sus intenciones de vender la virginidad de la niña. Al mismo tiempo, los vecinos de la calle de los Mataderos escuchan en la radio el anuncio de una tregua, por lo que organizan una fiesta y banquete en la calle, con los alimentos que atesoraba la Usurera en su casa. Sin embargo, la tregua se rompe antes de lo esperado y una de las balas de los francotiradores atraviesa a Alba, con lo que la alegría se torna nuevamente en desdicha.

Las mujeres y los niños son las principales víctimas de la guerra en Los días perdidos, al tener que lidiar no sólo con el hambre y la amenaza constante de las armas, sino también con las violaciones y la trata de blancas. A través del personaje de Pina, quien fue "repetidamente violada en un campo de concentración" (Hibernia, 1997: 13), se trata el tema de las violaciones masivas y las consecuencias traumáticas sobre las víctimas. La joven trata de evadirse de la cruel realidad de su embarazo y le pide a su amiga Martta que se haga pasar por su novio, consciente de que su hijo "vendrá con un pan de odio debajo del brazo" (76). Tomás, vendedor de lencería femenina, protagoniza algunos de los discursos más misóginos del drama, llevando hasta las últimas consecuencias la reducción del cuerpo de las mujeres a objeto del deseo masculino con el fin de vender su producto - "créame, señora, hasta las bestias son menos bestias ante unas bragas de algodón" (39)-. Sin embargo, no son sólo los hombres los que ejercen violencia sobre las mujeres. También la vieja Usurera intenta chantajear a Alba, ofreciéndole un cargamento de comida que evite que su madre se ponga en peligro en busca de alimentos, a cambio de su virginidad: "La inocencia sólo se pierde una vez, en verdad que es efímera, pero es necesario perderla. Mi niña, hay que arrimar el hombro. ¿Habéis comido hoy en casa?” (89).

En La ciudad sitiada $(1997)^{6}$, de Laila Ripoll, se busca la representación del drama de las víctimas de todas las guerras, situando

${ }^{6}$ La ciudad sitiada recibió el Premio Caja España de Teatro Breve en 1996. En España el texto cuenta con dos ediciones, una de 1997 y otra de 2003. La autora dirigió el primer montaje de esta obra realizado por la compañía Micomicón [Sala Cuarta Pared, 12-2-1999] y recibió el Premio a la Mejor Dirección en el Certamen de Directoras de Escena de Torrejón de Ardoz 1999 y el Premio "José Luis Alonso" a la Mejor Dirección, de la Asociación de Directores de Escena.

UNED. REI, 2 (2014), pp. 145-169

ISSN 2340-9029 
para ello la acción en una ciudad anónima, asediada por una guerra igualmente innominada. Esta falta de concreción de unas coordenadas espaciotemporales le permite al público extrapolar el drama de los personajes a su conocimiento sobre diferentes guerras, cuyas imágenes y recuerdos se hallan presentes en la conciencia colectiva ${ }^{7}$. Algunas de las anécdotas permiten pensar en la limpieza étnica llevada a cabo en las guerras de los Balcanes, otras, en el hambre y la miseria de las ciudades sitiadas durante la guerra civil española. En la puesta en escena, además, se utilizaron "músicas tradicionales latinoamericanas o de Croacia” (Toquero, 1999), y se escucharon piezas de $L a$ pasión según San Mateo, de Johann Sebastian Bach, cuyos títulos aparecen indicados en las acotaciones del texto y que tienen la función de intensificar el dramatismo de las escenas. La intención de presentar a las víctimas civiles de las guerras desde un punto de vista universal, se hace patente a través de la inclusión, al principio del texto, de una cita de la Numancia cervantina (Ripoll, 1997: 7). Con ella, se recupera un tema muy presente en la tradición dramática española y se establece una relación entre el pasado y el presente de las guerras, en los que la población civil sigue siendo un objetivo bélico.

La obra se estructura en 16 escenas breves, que transcurren en un escenario de "cascotes y ruinas entre los que los habitantes de la ciudad sitiada desempeñan sus trabajos cotidianos” (Ripoll, 1997: 11). Algunos rasgos estéticos habituales del teatro de Ripoll se observan ya en esta opera prima: la mezcla de elementos trágicos y cómicos, la corporeización de muertos vivientes en escena (Guzmán, 2012), el humor negro y la tendencia hacia lo grotesco y esperpéntico (Reck, 2012), que se hace notorio en las escenas que tratan el tema del ham-

${ }^{7}$ Según señalan Agnès Surbezy y Monique Martinez, La ciudad sitiada "se inscribe dentro de una atemporalidad frecuente en muchas obras contemporáneas. Si bien esta participa de una dimensión simbólica (se trata de todas las ciudades sitiadas del mundo y en todas las épocas), podemos cuestionar la ausencia de referente espaciotemporal, tanto más cuanto que viene asociado con una estructura fragmentada, de microsecuencias que se suceden, que a veces reaparecen para seguir el hilo tenue del tema que las estructura (la muerte del perro, la del niño, la violación de la mujer) formando un todo, un conjunto interrelacionado [...]" (2008: 318). bre. El tono agridulce del texto está inspirado, según Ripoll, en las historias contadas por "mujeres como nuestras abuelas, que fueron capaces de convertir en un cuento para los niños los duros años que les tocaron vivir desde 1936, que comenzó la Guerra Civil, hasta mediados de los años 40, cuando finalizaron las hambrunas" (J.S., 1999).

De manera similar a lo que ocurría en Los días perdidos, la situación gana protagonismo frente a los personajes, que actúan de forma coral. Mientras que en el texto de Hibernia existía una trama común que vertebraba las historias individuales de los personajes por su relación de vecindad, en La ciudad sitiada los monólogos y diálogos se presentan ante el público de forma aislada, sin que medie mayor trama común que la reiteración de ciertos temas y diálogos o el hecho de vivir en una ciudad sitiada. En consonancia con esto, los personajes creados por Ripoll carecen de nombres propios y aparecen identificados en función de su sexo o su edad -Hombre, Muchacha, Niño, Mujer Mayor...-.

Junto con el tema del hambre, retratado en varias de las escenas, destaca el de la violencia contra las mujeres, manifestada sobre todo a través de violaciones. La Mujer Joven explica cómo fue violada y golpeada en su propia casa por varios hombres - “Cerré los ojos para no verles / y pude probar hasta cinco babas distintas / hasta cinco alientos distintos, / cinco braguetas distintas / que olían todas igual" (29)-; una Mujer Mayor le advierte a su nieta que debe huir de los hombres "Guárdate de ellos. / Se arrastran como culebras / se meten en tu cama / como alacranes / te pican y escapan" (33)-; y una Madre explica que ha de prostituirse para poder alimentarse y amamantar a su bebé:

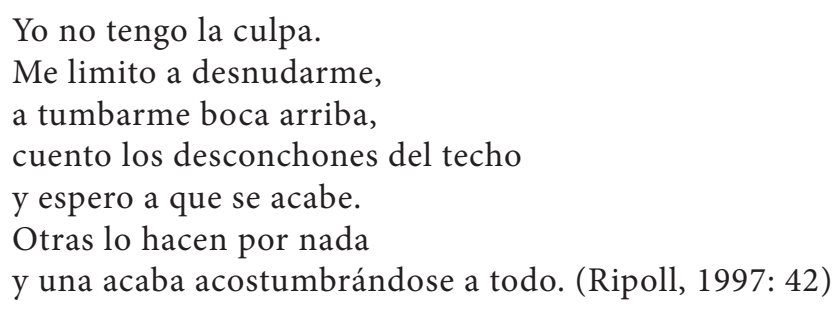

Al final de la obra, aparece también un Niño que representa 
los casos de abortos realizados a mujeres violadas por hombres de otra etnia. En su monólogo se refiere a los recuerdos agradables de la infancia y a las historias que su abuela le contaba de la guerra, hasta que, en un giro dramático, reconoce que todo lo que ha dicho no ocurrió nunca "porque yo no he nacido. / Me arrancaron del vientre de mi madre / porque era de otra raza" (Ripoll, 1997: 46).

En Un lugar estratégico $(2005)^{8}$, de Gracia Morales, las coordenadas espaciotemporales cobran una vital importancia, aunque, en este caso, no se trata de una ciudad sitiada, sino, como hemos anticipado, de un puente histórico convertido en enclave estratégico durante el transcurso de una guerra étnica. A pesar de que la autora busca la universalidad del tema y omite las referencias a un conflicto bélico concreto, afirma en una entrevista publicada en la prensa haberse inspirado en la destrucción del puente medieval de Mostar en 1993 durante la guerra (Martínez, 2003: 62). Por este motivo, tanto el puente de Mostar como el puente al que se alude en la obra son puentes "con Historia”, que datan del siglo XVI (Morales, 2005: 35).

Dos actrices y un actor se encargan de representar todos los papeles de la obra, que tiene lugar en tres tiempos históricos diferentes. La presencia alternante de personajes de tres generaciones diferentes y distinto sexo crea un juego de espejos en el que ambas comunidades enemistadas se posicionan frente al "Otro", considerado tanto en su faceta étnica como en la de género. Los cambios temporales se manifiestan a través de la luminotecnia y de un giro mecánico de la orientación del puente. Tan sólo uno de los personajes aparece en los tres tiempos de forma inmutable, la apátrida Vagabunda, un personaje intemporal que repite siempre las mismas frases, cargadas de simbolismo. Los otros dos actores muestran el desarrollo del conflicto a través de tres generaciones: la primera de ellas se sitúa en el momento de la guerra y las otras dos con posterioridad a la misma. Cada generación, representada por un hombre y una mujer -el Hombre soldado

${ }^{8}$ La obra fue merecedora del Premio Miguel Romero Esteo en 2003 y presentada como lectura dramatizada en su traducción al italiano [Teatro Belli, Roma, diciembre 2007]. y la Mujer Soldado, el Hombre y la Mujer, el Muchacho y la Muchacha-, tiene unas expectativas diferentes con respecto al "Otro".

La generación intermedia, conformada por el Hombre y la Mujer, se reúne en el puente casualmente durante un atardecer otoñal. Enseguida se identifican el uno al otro como extraños procedentes de comunidades que se enfrentaron en una guerra hace años, cuando los dos eran tan sólo unos niños. A pesar de los traumas y las diferencias que los separan, consiguen hablar del pasado, manifestando ciertas esperanzas sobre la reconciliación entre los pueblos:

НомвRE: Y tal vez, tal vez, llegue un día en que se pueda cruzar entero... De un lado a otro.

Mujer: (Se baja del pretil). Nosotros no veremos eso.

Hombre: Nosotros no... Pero más tarde, dentro de veinte años... Nuestros hijos o nuestros nietos... (Morales, 2005: 28)

El Hombre y la Mujer Soldado, por su parte, se conocen en una noche de invierno durante la guerra, cuando acuden al puente que divide a sus respectivas comunidades con la misión de detonarlo. La tercera generación, que puede identificarse con la de de los nietos de estos soldados, está protagonizada por dos muchachos enamorados que se reúnen en el puente en un mediodía de primavera y que, significativamente, remedan una escena de Romeo y Julieta. La guerra ha quedado atrás en el tiempo, pero los dos adolescentes encuentran un viejo fusil en el río que recuerda su nefasta existencia. Al final del drama y contra todo pronóstico, la Mujer y el Hombre Soldado detonan el puente, mostrando cómo aquellos encuentros fortuitos y los debates sobre la posibilidad y la voluntad de reconciliarse penden de un fino hilo.

El personaje de la Vagabunda, junto con el propio puente, sirve de conexión entre los tres tiempos históricos y comporta, en su inmutabilidad y en la iteración de sus frases, un halo de misterio y sabiduría. Lleva consigo un carro cargado de botas desemparejadas que simbolizan la fragmentación identitaria de las comunidades enfrentadas. Emmanuelle Garnier la considera una “metáfora del tiempo", dado “el 
aspecto cíclico de sus apariciones en la disposición de la obra" (2012: 76). La actitud de cada generación frente a la presencia de la Vagabunda -temor y desconfianza, en el caso de los Soldados, que no saben de qué bando está; sorpresa, en el caso del Hombre y la Mujer maduros, porque es capaz del cruzar el puente, algo prohibido para ellos; o complicidad, en el caso de los Muchachos- sirve también de indicador sobre los cambios producidos en la relación entre ambas comunidades. Ni el puente ni el discurso de la Vagabunda varían a lo largo del tiem$\mathrm{po}^{9}$, son las personas y su relación con el "Otro" las que cambian. Por ello, sólo los jóvenes enamorados, cuyas comunidades viven en una aparente armonía, son capaces de encontrar dos botas iguales.

Belgrado (2008) ${ }^{10}$, de Angélica Liddell, es la única obra incluida en esta selección en la que las referencias a las guerras de los Balcanes son directas. Tanto el espacio como el tiempo histórico se hallan claramente delimitados. La acción transcurre en Belgrado con posterioridad a la guerra, tras la muerte de Slobodan Milosevic el 11 de marzo de 2006 en la prisión del Tribunal Penal Internacional de La Haya. La primera escena de la obra se sitúa en el Museo de la Revolución de Belgrado, capital de la República de Serbia, mientras que otras escenas se producen en la habitación de un hotel, en el interior de un taxi o en un garaje. El subtítulo de la obra, Canta lengua el misterio del cuerpo glorioso, procede de los primeros versos de un himno litúrgico para la festividad católica del "Corpus Christi", compuesto por Santo Tomás de Aquino y titulado Pange lingua ("Canta lengua"). Las trece escenas que componen el texto dramático van asimismo encabezadas por títulos de cantos litúrgicos y gregorianos en latín, que en la mayoría de los casos van seguidos de la traducción de

9 "VAGABUnda: ¿Saben cuándo fue construido? [...] En el siglo XVI... Uhmmm, mucho tiempo... ¿Cuánto durará todavía? Quién lo sabe... Imagínense la de cosas que habrán visto estas piedras..." (Morales 2005: 17).

${ }^{10}$ Belgrado recibió el Premio Lope de Vega de 2007 y fue presentada como lectura dramatizada en el XIII Ciclo de Lecturas Dramatizadas de la SGAE, bajo la dirección de Carlos Bolívar [Teatro Español, Madrid, 26-5-2008] y llevada a escena por el alumnado de la RESAD, con la dirección de Alfonso Ramos [Sala Valle-Inclán, RESAD, Madrid, 12-1-2009].

UNED. REI, 2 (2014), pp. 145-169 algunos de sus versos. Aunque no se especifique en el texto, algunos de los cantos podrían estar pensados para escucharse o leerse durante la puesta en escena ${ }^{11}$. La sobriedad y la solemnidad litúrgica de los cantos conectan, en este sentido, con el contenido trágico de la obra dramática y la cadencia rítmica del lenguaje con que se expresan los personajes.

El texto dramático combina las escenas dialogadas, casi todas conformadas por largos monólogos que no impiden la comunicación entre los personajes, con escenas en las que se introducen breves fragmentos de declaraciones de personajes anónimos, siguiendo el estilo del teatro documento. De esta manera se conjuga el drama individual de los personajes con el drama colectivo de toda una sociedad afectada por las consecuencias de la guerra. El protagonista de la obra es Baltasar, hijo de un renombrado especialista en crímenes contra la Humanidad, que ha viajado a la República de Serbia con el fin de recabar información para su padre sobre la reacción de la sociedad belgradense ante la muerte de Milosevic. Lo que inicialmente es una investigación documental, se convierte en una indagación sobre la propia identidad del encuestador, que acaba por reconocer la influencia perniciosa que su padre ha tenido en su vida y la de toda la familia. Para llegar a esta conclusión, son necesarios una serie de encuentros con diversos personajes como Agnes, una corresponsal extranjera que ha cubierto diversos conflictos; Dragan, un serbio que trabaja en el Museo de la Revolución y vive atemorizado ante la presencia de antiguos criminales de guerra en la vida pública; o Zeljko, un paramilitar perteneciente a un grupo ultranacionalista serbio que secuestra al protagonista.

Como si de un héroe trágico contemporáneo se tratara, Baltasar recae en un error fatal al intentar socorrer a un hombre al que disparan en plena calle, ante la impasible actitud de los otros vian-

\footnotetext{
${ }^{11}$ Según comenta la autora en una entrevista: "trato la música como si fuera un personaje más en las obras, y también la utilizo de una manera primitiva, para entrar en otro estado emocional que me permita llegar hasta donde yo deseo, hasta algún límite que busco en ese momento" (Leguina, 2009: 17).
} 
dantes. Su intervención en pro de la víctima provoca que el asesino, Zeljko, lo secuestre poco después a él. Sin embargo, los dos hombres confraternizan al experimentar una peculiar anagnórisis que cambia para siempre la vida del protagonista: ambos han padecido desde la infancia la humillación de sus progenitores masculinos, a quienes achacan gran cantidad de perversiones y maldades en el ámbito familiar, que no se corresponden con la autoridad y el respeto de los que gozan en la Esfera pública. Tras esta revelación, Baltasar mantiene una conversación con Agnes en la que esta relaciona la situación de la madre de Baltasar con los efectos nocivos de la educación sentimental de las mujeres en sociedades machistas ${ }^{12}$, en las que estas son relegadas a un segundo plano mediante la sublimación de su función reproductiva:

La moral católica divide a las mujeres en tres,

Paridoras, vírgenes y rameras.

La mujer vive sometida a esas tres categorías,

Seis concepciones, un aborto y cinco partos, has dicho,

En cualquier caso ha vivido reducida al suburbio sentimen-

tal,

Excluida del mundo de las ideas [...]. (Liddell, 2008: 115)

De esta manera, Angélica Liddell conjuga en su obra la reflexión acerca de las consecuencias de la guerra de los Balcanes con otras formas de violencia menos evidentes que se hallan presentes en la vida pública y en la familiar. La actitud de la obra no es la de ofrecer respuestas, sino más bien la de suscitar interrogantes y cuestionar la visión difundida por los medios de comunicación sobre las guerras de la ex Yugoeslavia como un caso extraordinario o fatal. Al igual que en los otros textos, se mencionan las masacres, violaciones masivas y demás crímenes contra la humanidad que tuvieron lugar durante la guerra, además de plantearse otras cuestiones como la incapacidad del lenguaje para transmitir el sufrimiento humano, la doble moral

${ }^{12}$ Las nefastas consecuencias de la educación sentimental de las mujeres aparecen tratadas a menudo en la obra de las autoras dramáticas de principios de siglo (Nievade la Paz, 2012).

UNED. REI, 2 (2014), pp. 145-169 y la culpa del observador, representadas a través del trabajo de los corresponsales de guerra.

La segunda obra dramática escrita por Eva Hibernia en torno a las guerras de los Balcanes, laSal (2012) ${ }^{13}$, opta por la configuración de un cronotopo simbólico. La acción se sitúa en el año 2023 con el fin de mostrar las consecuencias de la barbarie sobre sus víctimas y verdugos. Según explica la autora en el prólogo, "en absoluto quería hacer teatro historicista. Es más, quise que la guerra de los Balcanes fuese trascendida por algo más grande, algo que pudiera darse en todos los tiempos" (Hibernia, 2012: 13-14). No obstante, en la descripción de los Dramatis Personae queda concretada la relación de los personajes con la realidad histórica: Salma es "superviviente de la guerra de los Balcanes" y "víctima de sistemáticas violaciones y torturas" (21), Solo es el "hijo de la violación de Áyax a Salma" que fue "adoptado por los señores Andersen, de Dinamarca" (21) y Áyax es un "criminal de guerra" y antiguo "militar perteneciente al ejército serbio durante la guerra de los Balcanes" (22). Los tres personajes de la obra componen una familia fantasma, forjada por la violencia en un campo de concentración durante la guerra.

Nuevamente nos encontramos con una configuración espaciotemporal determinante para la acción dramática. A pesar de las referencias a lugares concretos como autobuses, granjas o habitaciones de hotel, la ambientación sugerida por el texto dramático trasciende el espacio de lo real y logra erigirse en canal de la propia psicología de los personajes. Los espacios creados por la autora - "Soledades", "Ficciones", "Desiertos" y "Foto" - tienen una dimensión psico-simbólica y conforman las diferentes maneras a través de las cuales los personajes consiguen exteriorizar sus traumas. Tal y como Hibernia explica en el prólogo, en las "Soledades" se recoge el fluir de la conciencia de

${ }^{13}$ Presentada como lectura dramatizada bajo la dirección de Cristina Lügstenmann dentro del ciclo 'Primavera Vaca' [28-6-2010] y llevada a escena por la misma directora en el teatro La Caldera de Barcelona [29-11-2012]. Quisiera agradecer a Eva Hibernia que tuviera la amabilidad de facilitarme una copia del texto dramático, agotado en librerías en el momento de preparación de este ensayo.

UNED. REI, 2 (2014), pp. 145-169

ISSN 2340-9029 
cada personaje en solitario; en los "Desiertos" se reavivan sus recuerdos traumáticos del pasado; las "Ficciones" se componen de diálogos imaginarios con ese "Otro" fantasmagórico; y la "Foto" recoge la propia visión de los personajes sobre sí mismos.

Así pues, aparece la figura del verdugo, Áyax, considerado un monstruo tanto por Salma como por su hijo biológico, quien imagina su pasado violento. Áyax oculta su sentimiento de culpabilidad -mató a Hasija, su esposa musulmana, y a su hijo para demostrar su fidelidad a la causa serbia- en su obsesión por la fertilidad de sus tierras y la fecundidad de sus animales, considerándose a sí mismo una especie de gran patriarca, portador de "semillas santas" (40). Por otra parte, Salma es una mujer que trabaja en las cocinas de un hospital y que está profundamente marcada por su propia supervivencia a las violaciones y maltratos que le infringieron durante la guerra, cuando además le fue arrebatado el hijo que no deseaba. El joven Solo se la representa en su imaginación como una mujer feliz, que pudo rehacer su vida en Italia, aun cuando en sus "Ficciones" permanece acechante la figura ominosa del padre chetnik. Solo completa así este trío de soledades y heridas abiertas, pues representa a esa generación de hijos no deseados, nacidos de las violaciones étnicas. Al carecer de recuerdos sobre sus padres biológicos, busca en su trabajo de fotógrafo de guerra las respuestas que le permitan completar los vacíos de su identidad:

Un día, cuando tenía siete años, frente al objetivo, a bocaja-

rro les pregunté si yo era un hijo adoptado...

- Sí, dijeron.

- ¿Quiénes son mis padres?

- La guerra.

- ¿Dónde?

- En los Balcanes.

$-¿$ No hay fotografías?

- Sí, hay fotografías. Pero espera a verlas.

Por eso me hice fotógrafo,

para encontrar la imagen

que se me ha perdido de mi propia historia. (Hibernia, 2012:33)

Como ocurría en otros textos, laSal retoma temas que preocupan a la sociedad del presente como son los intereses ocultos de las guerras - "las víctimas somos muy necesarias para el delicado equilibrio de los beneficios y el orden mundial" (56) - y reflexiona sobre la culpa del observador a través de la figura del fotógrafo de guerra, que tiene que seleccionar la foto que "mejor condense el horror" y que consiga hablarle "al corazón de los hombres" (80).

\section{Conclusiones}

Dado que los hechos históricos en los que se inspiraron las autoras para la composición de estas obras formaban parten de una realidad acuciante o del pasado más reciente, no es de extrañar que sus procesos creativos se basen principalmente en la información recabada a través de los medios de comunicación. Las imágenes y fotografías difundidas a través de la televisión y la prensa se convierten así en elementos desencadenantes de los procesos dramáticos.

En líneas generales, las autoras muestran en sus obras una preferencia por los cronotopos simbólicos a la hora de representar el drama de la guerra. Desde la creación de espacios fantásticos de resonancias míticas, como el de la Isla del Sueño en Fuga, hasta la descontextualización de lugares reales e históricos, como el puente de Mostar en Un lugar estratégico, las autoras optan por propuestas que universalizan el drama de la guerra en un claro alegato antibelicista ( La ciudad sitiada, Los días perdidos). Tan sólo en Belgrado y en laSal se introducen referencias espacio-temporales directas a los hechos históricos, aunque sus creadoras se sirven para ello de mecanismos muy dispares: por una parte, el recurso a formas dramáticas propias del drama documento en Belgrado, y por otra, la configuración de un cronotopo abstracto, sugerido por la psicología de los personajes y sus traumas, en laSal.

En Fuga, Los días perdidos, La ciudad sitiada, Un lugar estratégico y laSal se da protagonismo a las víctimas civiles y anónimas de las guerras. En Belgrado, sin embargo, el protagonismo recae en la mi- 
rada externa sobre esas guerras, que se puede identificar como la visión mediatizada o la visión internacional y europea. Al situar el foco dramático en Baltasar, un observador "extranjero" que se halla en la zona del conflicto, las víctimas permanecen en el espacio del "Otro", que es el espacio que ocupan en la realidad. De esta manera, el "Otro" como personaje tiene una mayor capacidad para el cuestionamiento y la crítica, pues ya no es sólo la crueldad de la guerra y sus consecuencias lo que se denuncia en la obra, sino también la imposible imparcialidad y neutralidad del observador. Este tema, además, aparece tratado en breves pinceladas en otras obras, como ocurre en Los días perdidos, cuando uno de los personajes menciona que un periodista se paró a hacerle unas fotos por estar lisiado; o en laSal, cuando Solo se refiere a su trabajo como fotógrafo de guerra y a la búsqueda de imágenes con las que conmover e impactar al receptor.

Por último, cabe insistir en la relevancia que adquiere en todas las obras comentadas la posición de especial vulnerabilidad de las mujeres durante la guerra, sobre todo en lo que respecta al impacto de la violencia infringida a través de las violaciones en masa, en las que el cuerpo de las mujeres es utilizado para llevar a cabo una limpieza étnica. En las obras se hace referencia tanto al peligro y la consumación de estas violaciones (Fuga, La ciudad sitiada) como al trauma que conlleva para la vida de las mujeres y de la comunidad en la que se integran (Los días perdidos, Un lugar estratégico), llegando incluso a plantearse las consecuencias de esa desintegración familiar con el paso de los años (Belgrado, laSal). De esta manera, las autoras plantean al público interrogantes sobre la prevalencia de la violencia en las sociedades del presente e intentan suscitar en el público una reflexión sobre los prejuicios racistas y misóginos en que se basa, con el fin de generar una conciencia colectiva más proclive a la igualdad social y a la eliminación de todas las formas de violencia.

Recibido: $07 / 05 / 2014$

Aceptado: 10/07/2014

\section{Obras citadas}

"Angélica Liddell: algunas obras me surgen de una intensa necesidad interior de confesar una experiencia personal" (2008), Artez. Revista de las Artes Escénicas - Castilla y León, 134, http://www.revistadeteatro.com/artez/artez134/Entevista Liddell.htm. [consultado: 06-05-2014]

Araújo, Luis (1997), “Una jovencísima propuesta de teatro poético”, en Eva Hibernia, ed., Los días perdidos, Madrid: Asociación de Autores de Teatro, pp. 3-5.

García-Manso, Luisa (2012), “Inmigración femenina y desigualdad de género en las Artes escénicas: La orilla rica (1993), de Encarna de las Heras", en Francisca Vilches-de Frutos y Pilar Nieva-de la Paz, coord. y ed., Imágenes femeninas en la Literatura española y las Artes escénicas (siglos XIX y XX), Philadelphia: Society of Spanish and Spanish-American Studies, pp. 287304.

--- (2013), Género, identidad y drama histórico escrito por mujeres en España (1975-2010), Oviedo, KRK.

Floeck, Wilfried (2006), "Del drama histórico al teatro de la memoria. Lucha contra el olvido y búsqueda de la identidad en el teatro español reciente", en José Romera Castillo, ed., Tendencias escénicas al inicio del siglo XXI, Madrid: Visor Libros, pp. 185-209.

Galindo, Carlos (1995), “Fuga desembarca en el C. C. Galileo”, ABC, 6 diciembre, p. 81.

Garnier, Emmanuelle (2012), Lo trágico en femenino. Dramaturgas españolas contemporáneas, Bilbao: Artezblai.

Guzmán, Alison (2012), "Los muertos vivientes de la Guerra Civil en cinco obras de Laila Ripoll: La frontera, Que nos quiten lo bailao, Convoy de los 927, Los niños perdidos y Santa Perpetua", Don Galán. Revista de investigación teatral, 2, http://teatro.es/contenidos/donGalan/donGalanNum2/pagina. php? vol=2\&doc $=2 \_4$

Guzmán, Almudena (1999), "Capital del dolor. A las puertas de La ciudad sitiada, en Triángulo", $A B C, 15$ de mayo, p. 14.

Herrero, Carmen (2001), "Sangre mítica: el tratamiento de la guerra en la dramaturgia de Itziar Pascual y Eva Hibernia", en Francisco Torres Monreal, ed., El teatro y lo sagrado: de Michel de Ghelderode a Fernando Arrabal, Mur- 
cia: Servicio de Publicaciones de la Universidad de Murcia, pp. 347-59.

Hibernia, Eva (1997), Los días perdidos, Madrid: Asociación de Autores de Teatro.

--- (2012), laSal, Barcelona: Teatre Expres, Anna B’koaj Edicions i produccions.

J. S. (1999), "La ciudad sitiada: homenaje a las mujeres que sufren la guerra", Burgos 7 Días, 17 noviembre.

Leguina, Leire (2009), “Angélica Liddell. Pornografía del alma”, Revista Metal, febrero-marzo, p. 17.

Liddell, Angélica (2008), Belgrado. Canta lengua el misterio del cuerpo glorioso, Bilbao: Artezblai.

Martínez, Lara (2003), “Gracia Morales: los jóvenes escritores aún no somos incuestionables”, $A B C$ (Sevilla), 27 octubre, p. 62.

Morales, Gracia (2005), Un lugar estratégico, en Gracia Morales Ortiz y Gonzalo Lloret Marín, Premio Miguel Romero Esteo 2003 n4. Un lugar estratégico / Hasta que la muerte. Degeneración en nueve escenas, Sevilla: Junta de Andalucía / Consejería de Cultura, pp. 7-37.

Nieva-de la Paz, Pilar (2012), "Imágenes femeninas entre dos tiempos en el teatro de una escritora exiliada: La señora Florentina y su amor Homero, de Mercè Rodoreda", Anales de la Literatura Española Contemporánea, 37.2, pp. 339-60.

"No te lo pierdas" (2002), Campus [El Mundo], 26 abril, p. 100.

Pascual, Itziar (1994), Fuga, en Itziar Pascual / Encarna de las Heras / Sara Molina / Liliana Costa, Fuga / La orilla rica / El último gallo de Atlanta / El sello de la necesidad, Madrid: Ministerio de Cultura / Centro Nacional de Nuevas Tendencias Escénicas, pp. 11-26.

--- (2005), Fuga. CELCIT (Centro Latinoamericano de Creación e Investigación Teatral), http://www.celcit.org.ar/bajarArchivo.php?id=200\&t=publica ciones\&c=dla\& e=pdf\&f=200.pdf [consulta: 06-05-2014]

Ragué-Arias, María-José (2005), "Del mito contra la dictadura al mito que denuncia la violencia y la guerra”, en $M^{\text {a }}$ Francisca Vilches de Frutos, dir., Mitos e identidades en el teatro español contemporáneo. Foro Hispánico. Revista Hispánica de Flandes y Holanda, 27, abril, pp. 11-21.
Reck, Isabelle (2012), "El teatro grotesco de Laila Ripoll, autora”, Signa, 21, pp. 55-84.

Ripoll, Laila (1997), La ciudad sitiada, en Adeilada Ripoll Cuetos / Agapito Martínez, La ciudad sitiada / Zapateros subterráneos. Premio Caja España de Teatro Breve 1996, Valladolid: Caja España, pp. 3-49.

-- (2011), “Santa Perpetua y la Trilogía Fantástica”, Primer Acto, 337, pp. 25-38.

Serrano, Virtudes (2004), "Dramaturgia femenina fin de siglo. Estado de la cuestión", Arbor, 177. 699-700, pp. 561-572.

Surbezy, Agnès y Monique Martinez (2008), "El tratamiento cuántico de la historia en la dramaturgia femenina actual", en Wilfried Floeck, Herbert Fritz y Ana García Martínez, eds., Dramaturgias femeninas en el teatro español contemporáneo: entre pasado y presente, Hildesheim / Zürich / New York: Georg Olms, pp. 315-28.

Toquero, Carlos (1999), "Lo más duro es el silencio", El Mundo (Valladolid), 16 noviembre.

Vilches de Frutos, Francisca (1999), “Teatro histórico: la elección del género como clave de la escena española contemporánea”, en José Romera Castillo y Francisco Gutiérrez Carbajo, eds. Teatro histórico (1975-1998). Textos y representaciones, Madrid: Visor, pp. 73-92.

--- (2002), “Teatro y memoria: la recreación del mundo rural en Las manos, de José Ramón Fernández, Yolanda Pallín y Javier G. Yagüe”, Revista de Literatura, LXIV, 127, pp. 235-45.

Yuval-Davis, Nira (1997), "Ethnicity, Gender Relations and Multiculturalism", en Debating Cultural Hybridities. Multicultural Identities and the Politics of Anti-Racism, London / New Jersey: Zed Books, pp. 193-209.

Zambrano, María (1983), La tumba de Antígona, Litoral 121-23, pp. 17-84. 